\title{
Efeito de Dois Níveis de Lisina e do Sexo sobre o Rendimento e Qualidade da Carne de Peito de Frangos de Corte
}

\author{
Ibiara Correia de Lima Almeida ${ }^{1}$, Ariel Antonio Mendes ${ }^{2}$, Edson Gonçalves de Oliveira ${ }^{3}$, \\ Rodrigo Garófallo Garcia ${ }^{1}$, Edivaldo Antonio Garcia ${ }^{2}$
}

RESUMO - Um experimento foi realizado para avaliar o efeito de dois níveis de lisina na dieta sobre o rendimento e qualidade da carne de peito de frangos de corte. Dois mil pintos de um dia da linhagem Ross foram distribuídos em um delineamento inteiramente casualizado, em esquema fatorial 2 x 2 (dois sexos e dois níveis de lisina). As aves foram alimentadas com dietas iniciais ( 1 a 21 dias), crescimento (22 a 42 dias) e acabamento (43 a 49 dias), contendo $100 \%$ dos níveis de lisina recomendados pelo NRC (1994), ou 110\% nas rações iniciais e de crescimento e $120 \%$ na ração de acabamento. Dessa maneira, os níveis de lisina recomendados foram de $1,10,1,00$ e $0,85 \%$,respectivamente, enquanto os níveis considerados altos foram de 1,21, 1,10 e 1,02\%, respectivamente, nas rações iniciais, de crescimento e de acabamento. As aves foram abatidas aos 28, 35, 42 e 49 dias de idade para avaliar o rendimento e a qualidade da carne do peito. Os níveis de lisina não afetaram os valores de $\mathrm{pH}$, a composição química da carne de peito e a perda de peso por cozimento. A altura, largura e o comprimento do peito apresentaram menores valores, em todas as idades, nas aves alimentadas com níveis altos de lisina. Com base nos resultados obtidos neste trabalho, conclui-se que os níveis de lisina recomendados pelo NRC (1994) são adequados para maximizar o rendimento e a qualidade do peito de frangos de corte.

Palavras-chave: carne de peito, frangos de corte, lisina, qualidade da carne

\section{Effect of Two Lysine Levels and Sex on Carcass Yield and Breast Meat Quality of Broiler Chickens}

\begin{abstract}
An experiment was conducted to evaluate the effect of dietary lysine levels and sex on breast yield and breast meat quality. Two thousand Ross day-old chicks were reared in a 2x2 randomized factorial design (two sex and two dietary lysine levels). Birds fed starter diets (1 - 21 days), growing (22 - 42 days) and finishing (42 - 49 days) with 100\% of NRC (1994) lysine requirement, or $110 \%$ in the starter and growing and $120 \%$ in the finishing diets. Recommended lysine levels were $1.10,1.00$ and .85\%, while high lysine levels were 1.21, 1.10 and 1.02\%, respectively, for starter, growing and finishing diets. Broilers were slaughtered at $28,35,42$ and 49 days of age for breast meat evaluation. Dietary lysine level did not affect breast meat $\mathrm{pH}$, chemical composition, cooking loss and tenderness. Breast height, width and length were lower, at all ages, when broilers fed diets with high lysine levels. It was concluded that recommended NRC (1994) lysine levels are adequate to maximize breast meat yield and quality.
\end{abstract}

Key Words: breast meat, broiler chickens, lysine, meat quality

\section{Introdução}

A produção de filés de peito para atender às necessidades de indústrias de pós-processados ou restaurantes de comidas rápidas tem implicações econômicas importantes para a rentabilidade dos produtores avícolas. Desta forma, existe hoje, uma grande preocupação com o rendimento do peito desossado e com sua qualidade sensorial, principalmente quanto a qualidade pós-abate, representada pela maciez, pH, cor, suculência, sabor, au- sência de contaminação e vida de prateleira, bem como quanto a ausência de calos de peito, hematomas e hemorragias.

Como demonstrado na literatura, o comprimento, peso e espessura do filé de peito de frangos de corte são afetados pela linhagem, sexo e idade das aves. Filés mais longos, espessos e pesados são produzidos pelas aves mais velhas e pelos machos (Robinson et al., 1996 a,b). O aumento na massa corporal é devido principalmente à espessura do músculo pectoralis major (Lubritz, 1997).

\footnotetext{
${ }^{1}$ Alunos do Programa de Pós-Graduação em Zootecnia, Área de Concentração em Nutrição e Produção Animal da FMVZ-UNESP, Botucatu-SP. E.mail: ibiara@fca.unesp.br ou ibiara@yahoo.com; garofallo@fca.unesp.br

${ }^{2}$ Docente do Depto. De Produção e Exploração Animal da FMVZ-UNESP, Botucatu-SP. E.mail: arielmendes@fca.unesp.br; egarcia@fca.unesp.br

3 Docente do Depto. de Zootecnia, Setor de Ciências Agrárias da Universidade Federal do Paraná. E.mail: egomima@terra.com.br Endereço: Departamento de Produção e Exploração Animal. FMVZ/UNESP - Fazenda Lageado. Caixa Postal - 560. CEP: 18618-000
} 
Lubritz (1997) encontrou efeito da linhagem e do sexo sobre o comprimento, espessura e peso do peito, sendo que as linhagens selecionadas para taxa de crescimento apresentam filés mais longos que as linhagens selecionadas para alto rendimento de carcaça. Em contraste, as linhas selecionadas com maior ênfase em conformação e rendimento apresentam filés mais curtos, espessos e pesados. O autor encontrou também uma correlação positiva entre o comprimento, largura e espessura do filé com o peso do filé, peso total de carne branca e porcentagem de carne branca.

Em relação à composição química da carcaça, diversos pesquisadores relatam (Summers \& Leeson, 1985, Summers et al., 1992, Holsheimer \& Ruesink, 1993) que o nível de lisina da dieta afeta esse parâmetro, sendo que níveis mais altos desse aminoácido proporcionam maiores porcentagens de proteína na carcaça.

Outro critério importante para a determinação da qualidade da carne é a capacidade de retenção de água, que é a capacidade do músculo e de produtos cárneos em manter a água ligada em condições específicas. A sua importância reside no fato de que essa característica está relacionada com o aspecto da carne antes do cozimento, comportamento durante a cocção e palatabilidade do produto (Bressan, 1999).

Quando a carne de peito é o objetivo da produção, a lisina merece atenção especial, pois ela é o segundo aminoácido limitante em dietas comerciais para aves. Sua principal função é a síntese protéica, sendo que seu nível corporal é duas vezes maior que os níveis de aminoácidos sulfurados e treonina (Pack, 1995).

O objetivo do presente experimento foi avaliar comprimento, largura, altura, peso, $\mathrm{pH}$, perda de peso por cozimento e composição química da carne de peito de frangos de corte machos e fêmeas alimentados com dietas com dois níveis de lisina.

\section{Material e Métodos}

O experimento foi realizado nas instalações experimentais da Faculdade de Medicina Veterinária e Zootecnia da UNESP, Campus de Botucatu. Foram utilizados 2000 pintos de um dia da linhagem Ross, sexados e distribuídos em 40 boxes de $5,0 \mathrm{~m}^{2}$ cada, com 10 aves $/ \mathrm{m}^{2}$.

$\mathrm{O}$ delineamento experimental adotado foi em blocos inteiramente casualizados com arranjo fatorial de 2x2 (dois níveis de lisina e dois sexos), com 10 repetições de 50 aves cada. Os níveis de lisina comparados foram aqueles recomendados pelo NRC (1994), em cada fase de criação $(1,10,1,00$ e $0,85 \%$ de lisina, respectivamente nas rações inicial, crescimento e acabamento) e níveis superiores a esses, sendo $110 \%$ das recomendações nas rações inicias $(1,21 \%$ de Lis) e de crescimento ( $1,10 \%$ de Lis) e de $120 \%$ na ração de acabamento (1,02\% de Lis). Para a obtenção dos níveis superiores de lisina foi adicionada lisina sintética nas rações basais, conforme apresentado na Tabela 1.

As aves foram pesadas com um dia de idade e partir do $28^{\circ}$ dia de idade semanalmente para avaliar o desenvolvimento corporal, sendo a mortalidade controlada. Aos 28, 35, 42 e 49 dias de idade, foram amostradas duas aves de cada parcela experimental perfazendo um total de 20 aves por tratamento em cada idade de abate, sendo que a escolha das aves foi feita dentro da faixa de peso de $10 \%$ acima ou abaixo da média de peso do boxe. As aves foram abatidas após um jejum de 8 horas no abatedouro experimental da FMVZ. As características avaliadas neste experimento foram: rendimento de peito, comprimento, altura e largura do peito, perda de peso por cozimento, força de cisalhamento e composição química da carne de peito de frangos de corte.

As análises de rendimento de peito foram realizadas segundo metodologia descrita por Mendes (1990). Para determinação de $\mathrm{pH}$ utilizou-se um eletrodo de penetração, diretamente no peito das aves 24 horas post mortem. Essa medida foi realizada em todas as aves amostradas para a determinação do rendimento de carcaça e das partes.

O comprimento, largura e altura do peito foram determinados tomando-se os músculos pectoralis major. Após dissecados, pesados e medidos, considerou-se como valores finais as médias de dois filés por ave. Para essas medidas utilizou-se um paquímetro, sendo que a altura foi medida na parte mais espessa do músculo.

Para determinação da perda de peso por cozimento, foi utilizada a porção esquerda dos músculos peitorais de todas as aves abatidas (20 aves/ tratamento, com quatro tratamentos). As amostras, após numeradas e identificadas, foram pesadas em balança semi-analítica, embaladas em papel alumínio e cozidas em chapa elétrica com resistência em ambas as faces, a $180^{\circ} \mathrm{C}$ até que atingissem temperatura entre 82 a $85^{\circ} \mathrm{C}$. Após uma hora sendo resfriadas

R. Bras. Zootec., v.31, n.4, p.1744-1752, 2002 
Tabela 1 - Composição percentual e calculada das rações experimentais

Table 1 - Percentual and calculate composition of the experimental diets

\begin{tabular}{|c|c|c|c|c|c|c|}
\hline \multirow[t]{3}{*}{$\begin{array}{l}\text { Ingredientes } \\
\text { Ingredients }\end{array}$} & \multicolumn{6}{|c|}{$\begin{array}{l}\text { Fases (dias) e Níveis de lisina } \\
\text { Period (days) and Lysine levels }\end{array}$} \\
\hline & \multicolumn{2}{|c|}{$01-21$} & \multicolumn{2}{|c|}{$22-42$} & \multicolumn{2}{|c|}{$43-49$} \\
\hline & $1,10(\%)$ & $1,21(\%)$ & $1,00(\%)$ & $1,10(\%)$ & $0,85(\%)$ & $1,02(\%)$ \\
\hline $\begin{array}{l}\text { Milho moído } \\
\text { Corn }\end{array}$ & 61,00 & 61,00 & 61,88 & 61,88 & 63,67 & 63,67 \\
\hline $\begin{array}{l}\text { Farelo de soja } \\
\text { Soybean meal }\end{array}$ & 34,20 & 34,20 & 30,00 & 30,00 & 28,20 & 28,20 \\
\hline $\begin{array}{l}\text { Óleo vegetal } \\
\text { Veg. oil }\end{array}$ & 0,72 & 0,72 & 4,00 & 4,00 & 4,30 & 4,30 \\
\hline $\begin{array}{l}\text { Calcário calcítico } \\
\text { Limestone }\end{array}$ & 0,87 & 0,87 & 0,32 & 0,32 & 0,33 & 0,33 \\
\hline $\begin{array}{l}\text { Fosfato bicálcico } \\
\text { Dicalcium phosfate }\end{array}$ & 2,00 & 2,00 & 2,70 & 2,70 & 2,60 & 2,60 \\
\hline $\begin{array}{l}\text { Premix vitamínico } \\
\text { Vitamin mix }\end{array}$ & 0,40 & 0,40 & 0,40 & 0,40 & 0,40 & 0,40 \\
\hline $\begin{array}{l}\text { Premix mineral } \\
\text { Mineral mix }\end{array}$ & 0,12 & 0,12 & 0,12 & 0,12 & 0,12 & 0,12 \\
\hline $\begin{array}{l}\text { DL-Metionina } \\
\text { DL-Methionine }\end{array}$ & 0,23 & 0,23 & 0,10 & 0,10 & 0,00 & 0,00 \\
\hline $\begin{array}{l}\text { L-Lisina } \\
\text { L-Lysine }\end{array}$ & 0,01 & 0,11 & 0,00 & 0,13 & 0,00 & 0,08 \\
\hline $\begin{array}{l}\text { Sal } \\
\text { Salt }\end{array}$ & 0,35 & 0,35 & 0,35 & 0,35 & 0,30 & 0,30 \\
\hline $\begin{array}{l}\text { Inerte } \\
\text { Inert }\end{array}$ & 0,10 & 0,00 & 0,13 & 0,00 & 0,08 & 0,00 \\
\hline $\begin{array}{l}\text { Total } \\
\text { Total }\end{array}$ & 100 & 100 & 100 & 100 & 100 & 100 \\
\hline $\begin{array}{l}\text { Valor calculado } \\
\text { Calculated values }\end{array}$ & & & & & & \\
\hline $\begin{array}{l}\mathrm{EM}^{* *}(\mathrm{kcal} / \mathrm{kg}) \\
M E\end{array}$ & 2950 & 2950 & 3150 & 3150 & 3200 & 3200 \\
\hline $\begin{array}{l}\text { Proteína bruta (\%) } \\
\text { Crude potein }\end{array}$ & 21,00 & 21,00 & 19,00 & 19,00 & 19,00 & 19,00 \\
\hline $\begin{array}{l}\text { Cálcio (\%) } \\
\text { Calcium }\end{array}$ & 0,95 & 0,95 & 0,90 & 0,90 & 0,88 & 0,88 \\
\hline $\begin{array}{l}\text { P total }(\%) \\
\text { P total }\end{array}$ & 0,48 & 0,48 & 0,60 & 0,60 & 0,58 & 0,58 \\
\hline $\begin{array}{l}\text { Lisina }(\%) \\
\text { Lysine }\end{array}$ & 1,10 & 1,21 & 1,00 & 1,10 & 0,85 & 1,02 \\
\hline $\begin{array}{l}\text { Metionina }+ \text { Cistina }(\%) \\
\text { Methionine }+ \text { Cystine }\end{array}$ & 0,90 & 0,90 & 0,72 & 0,72 & 0,60 & 0,60 \\
\hline
\end{tabular}

* Premix vitamínico e mineral fornecidos pela Poli Nutri Alimentos Ltda (Vitamin mix and Mineral mix provided by Poli Nutri Alimentos Ltda). Premix Vitamínico (Vitamin Mix): Vit. A- 1.875.000 UI; Vit. D3- 625.000 UI; Vit. E- 3.750 mg; Vit. K3- 300 mg; Tiamina (Thiamin) - 375 mg; Riboflavina (Riboflavin) - 1.375 mg; Piridoxina (Piridoxine) - 500mg; Vit. B12- 3125 mg; Niacina (Niacin) - 8750 mg; Pantotenato de Cálcio (Calcium pantothenate) - 2500 mg; Ácido fólico (Folic acid) - 150 mg; Biotina (Biotin) - 15 mg; Colina (Choline) - 87.500 mg; Promotor de Crescimento (Growth pomoter) - $10.000 \mathrm{mg}$; Coccidiostático- $25.000 \mathrm{mg}$; Antioxidante (Antioxidant) - $5.000 \mathrm{mg}$. Premix Mineral (Mineral Mix): Fe - 50.000 mg; Cu - 70.000 mg; Mn - 60.000; Zn - 50.000 mg; I - 1.250 mg; Se - 200mg. ${ }^{* *}$ EM = Energia metabolizável (Metabolic energy).

em temperatura ambiente e a umidade superficial retirada com papel absorvente estas amostras foram pesadas e a diferença entre os pesos correspondeu à perda de peso por cozimento (Honikel, 1987). A força de cisalhamento (maciez) foi determinada nas mesmas amostras utilizadas para perda de peso por cozimento. Para tal deter- minação foram retiradas três amostras de cada peito, na forma de paralelepípedos com aproximadamente $2 \times 2 \times 1,13 \mathrm{~cm}$ as quais foram colocadas com as fibras orientadas no sentido perpendicular à lâmina do aparelho Warner-Bratzler, acoplado ao aparelho Instron M2318, conforme a metodologia descrita por Froning et al. (1978). 
A determinação da composição química do peito (umidade, proteína, extrato etéreo e cinzas) foi realizada utilizando-se partes dos músculos pectoralis major remanescentes das determinações do comprimento, largura e altura, sem pele e gordura de quatro aves por parcela, independente do sexo, escolhidas ao acaso, totalizando 32 amostras. As análises foram realizadas em duplicata e seguiram a metodologia preconizadas pela AOAC (1990)

As análises estatísticas dos resultados foram realizadas utilizando-se o pacote SAEG, segundo Euclides (1983). Para composição química da carne de peito, optou-se por se fazer uma análise de regres- são entre idades, eliminando-se a variável sexo, visto que diferenças entre sexo para estas características são pouco representativas.

\section{Resultados e Discussão}

Os resultados encontrados para rendimento de peito e carne de peito são apresentados na Tabela 2.

A utilização de níveis mais altos do aminoácido ocasionou aumento $(\mathrm{p}<0,05)$ no rendimento de peito das aves apenas aos 49 dias, com as fêmeas apresentando maiores resultados. Para porcentagem de carne de peito, os machos apresentaram diferença

Tabela 2 - Rendimento do peito e partes do peito de frangos de corte submetidos a níveis recomendados (LR) e superiores (LS) de lisina dietética

Table 2 - Total and parts breast yield of broilers chickens fed recomended (LR) and high (LS) dietary lysine levels

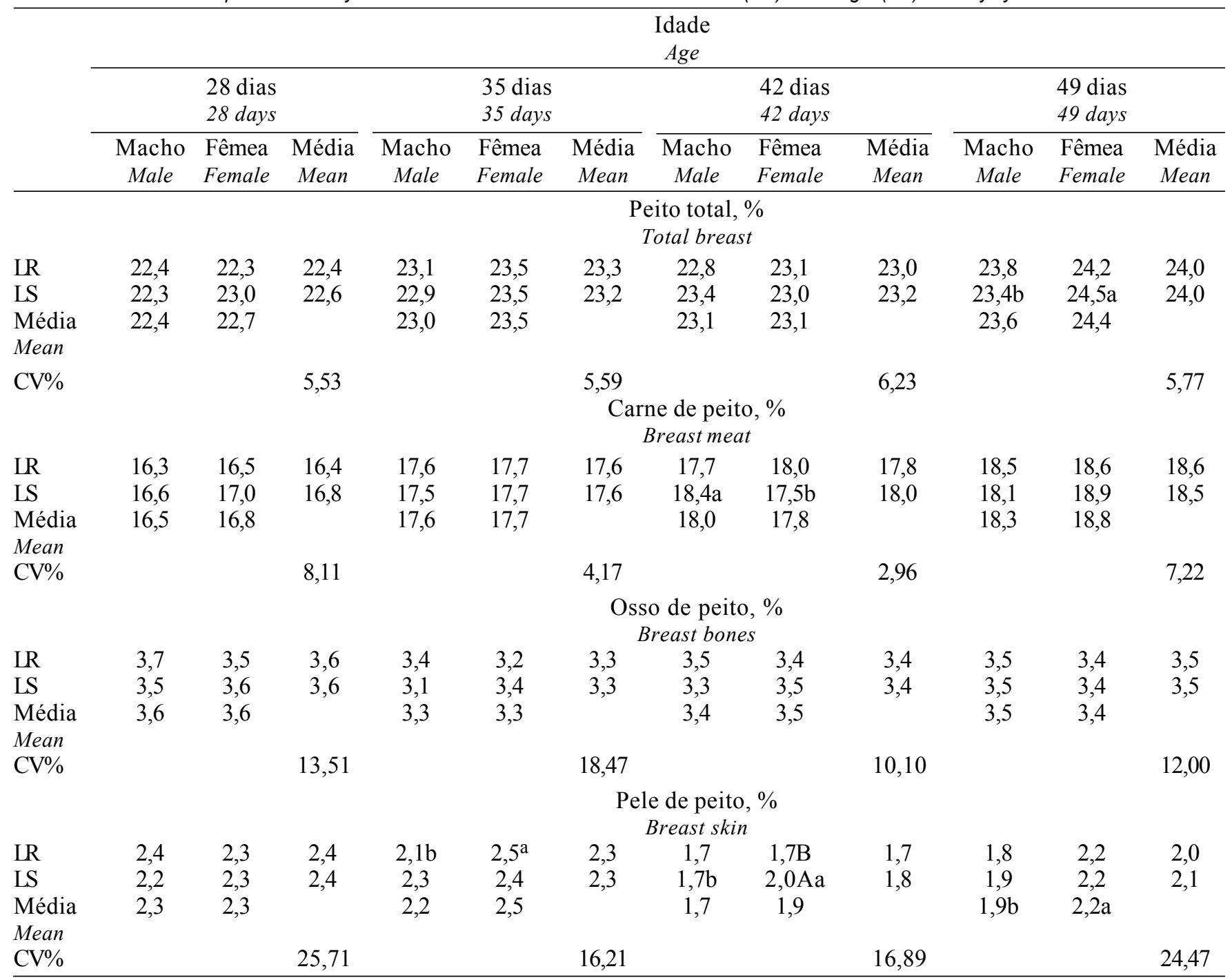

Rendimento $=$ (peso da carcaça ou parte/peso vivo) $\times 100$. Yield (carcass weight or part/live weight) $\times 100$.

$a, b$ Na linha, indica diferenças significativas entre sexos dentro de cada nível de lisina $(p<0,05) ; A, B$ na coluna, indica diferenças significativas entre níveis de lisina dentro de cada sexo $(p<0,05)\left({ }^{a, b}\right.$ in the line indicates significant differences between sexes form each lysine level ( $p<.05) ; A, B$ in the row indicates significant differences between sexes $(p<.05)$.

R. Bras. Zootec., v.31, n.4, p.1744-1752, 2002 
$(\mathrm{p}<0,05)$, aos 42 dias de idade, com maiores valores dentro do nível mais alto de lisina, sendo que essa diferença não se evidenciou nas outras idades estudadas. Resultados semelhantes foram encontrados por Moran (1992), que também não encontrou vantagens no rendimento de peito, quando utilizou níveis superiores de lisina que os recomendados pelo NRC (1984). Hickling et al. (1990) observaram resultados contraditórios, alcançando máximo rendimento de carne de peito, ao utilizarem níveis de lisina $12 \%$ superiores aos normalmente recomendados. Aos 42 dias, ocorreu ainda uma interação que proporcionou maior rendimento de pele nas fêmeas $(\mathrm{p}<0,05)$ alimentadas com maior nível de lisina. Este efeito desapareceu aos 49 dias, permanecendo apenas a diferença entre sexos.

Os resultados encontrados nas medições de $\mathrm{pH}$, perda de peso por cozimento e força de cisalhamento seguem na Tabela 3.

Para os valores de $\mathrm{pH}$ não houve interação entre lisina e sexo em nenhuma das idades assim como também não houve diferença significativa $(p>0,05)$ entre os níveis de lisina bem como entre os sexos nas diferentes idades analisadas. Segundo Lehninger et al. (1995), os valores de $\mathrm{pH}$ encontrados para carne variam entre 6,1 e 7,4. A literatura cita valores semelhantes aos encontrados neste trabalho para $\mathrm{pH}$ da carne de peito, sem diferenças entre os sexos (Jones \& Grey, 1989; Sams \& Mills, 1993). Já Pavan et al. (2001) encontraram diferenças para valores de $\mathrm{pH}$ da carne de peito de frangos de corte alimentados com diferentes níveis de lisina.

Aos 49 dias de idade foi encontrada diferença $(\mathrm{p}<0,05)$ entre sexos para perda de peso por cozimento, sendo que as fêmeas apresentaram maiores porcentagens de perda. Também nessa idade observou-se interação $(p<0,05)$ entre o nível de lisina alto e sexo, sendo que a carne de peito das fêmeas sofreram maior perda de peso por cozimento que a carne de machos. A literatura cita valores que variam entre 21,66 e $29,03 \%$ para perda de peso por cozimento para carne de peito de frangos de corte (Bressan, 1999; Mendes et al., 2001).

Não se observou correlação $(\mathrm{p}>0,05)$ entre perda

Tabela 3 - Valores de $\mathrm{pH}$, perda de peso por cozimento e força de cisalhamento da carne de peito de frangos de corte submetidos a níveis recomendados (LR) e superiores (LS) de lisina dietética

Table $3-\mathrm{pH}$, cooking loss and shear force values of meat breast of broilers fed recommended (LR) and high (LS) dietary lysine levels

\begin{tabular}{|c|c|c|c|c|c|c|c|c|c|c|c|c|}
\hline & \multicolumn{12}{|c|}{$\begin{array}{l}\text { Idade } \\
\text { Age }\end{array}$} \\
\hline & \multicolumn{3}{|c|}{$\begin{array}{l}28 \text { dias } \\
28 \text { days } \\
\end{array}$} & \multicolumn{3}{|c|}{$\begin{array}{l}35 \text { dias } \\
35 \text { days }\end{array}$} & \multicolumn{3}{|c|}{$\begin{array}{l}42 \text { dias } \\
42 \text { days }\end{array}$} & \multicolumn{3}{|c|}{$\begin{array}{l}49 \text { dias } \\
49 \text { days }\end{array}$} \\
\hline & $\begin{array}{c}\text { Macho } \\
\text { Male }\end{array}$ & $\begin{array}{l}\text { Fêmea } \\
\text { Female }\end{array}$ & $\begin{array}{l}\text { Média } \\
\text { Mean }\end{array}$ & $\begin{array}{c}\text { Macho } \\
\text { Male }\end{array}$ & $\begin{array}{l}\text { Fêmea } \\
\text { Female }\end{array}$ & $\begin{array}{l}\text { Média } \\
\text { Mean }\end{array}$ & $\begin{array}{c}\text { Macho } \\
\text { Male }\end{array}$ & $\begin{array}{l}\text { Fêmea } \\
\text { Female }\end{array}$ & $\begin{array}{l}\text { Média } \\
\text { Mean }\end{array}$ & $\begin{array}{c}\text { Macho } \\
\text { Male }\end{array}$ & $\begin{array}{l}\text { Fêmea } \\
\text { Female }\end{array}$ & $\begin{array}{l}\text { Média } \\
\text { Mean }\end{array}$ \\
\hline \multirow{6}{*}{$\begin{array}{l}\text { LR } \\
\text { LS } \\
\text { Média } \\
\text { Mean } \\
\text { CV\% }\end{array}$} & & & & & & & $\mathrm{pH}$ & & & & & \\
\hline & 6,00 & 6,02 & 6,01 & 6,07 & 6,05 & 6,06 & 6,04 & 6,02 & 6,03 & 6,07 & 6,01 & 6,04 \\
\hline & 6,02 & 6,04 & 6,03 & 5,97 & 6,02 & 6,00 & 5,96 & 6,00 & 5,98 & 6,09 & 6,05 & 6,07 \\
\hline & 6,01 & 6,03 & & 6,02 & 6,04 & & 6,00 & 6,01 & & 6,08 & 6,03 & \\
\hline & & & 3,25 & & & 2,18 & & & 2,13 & & & 2,15 \\
\hline & \multicolumn{12}{|c|}{$\begin{array}{c}\text { Perda de peso por cozimento, } \% \\
\text { Cooking loss }\end{array}$} \\
\hline LR & 24,66 & 24,61 & 24,63 & 23,67 & 22,92 & 23,29 & 22,57 & 22,33 & 22,44 & 21,55 & 22,76 & 22,15 \\
\hline LS & 23,61 & 24,80 & 24,22 & 21,58 & 23,16 & 22,37 & 23,29 & 22,83 & 23,06 & $21,41^{\mathrm{b}}$ & $24,55^{\mathrm{a}}$ & 22,98 \\
\hline Média & 24,15 & 24,70 & & 22,66 & 23,04 & & 22,94 & 22,58 & & $21,48^{\mathrm{B}}$ & $23,65^{\mathrm{A}}$ & \\
\hline Mean & & & & & & & & & & & & \\
\hline \multirow[t]{3}{*}{$\mathrm{CV} \%$} & & & 13,80 & & & 16,35 & & & 14,27 & & & 17,59 \\
\hline & \multirow{2}{*}{\multicolumn{12}{|c|}{$\begin{array}{l}\text { Força de cisalhamento, } \mathrm{kgf} / \mathrm{g} \\
\text { Shear force }\end{array}$}} \\
\hline & & & & & & & & & & & & \\
\hline LS & 2,45 & 2,80 & 2,62 & 3,21 & 3,02 & 3,12 & 4,28 & 4,23 & 4,26 & 3,77 & 3,98 & 3,88 \\
\hline Média & 2,52 & 2,58 & & 3,44 & 3,18 & & 4,01 & 4,70 & & 3,64 & 3,78 & \\
\hline $\begin{array}{l}\text { Mean } \\
\text { CV\%\% }\end{array}$ & & & 3554 & & & 3241 & & & 4217 & & & 3224 \\
\hline
\end{tabular}

R. Bras. Zootec., v.31, n.4, p.1744-1752, 2002 
de peso por cozimento e $\mathrm{pH}$. Resultados diferentes foram encontrados por Kim et al. (1988), constatando que médias inferiores de $\mathrm{pH}$ relacionavam-se com os maiores dados de perda de peso por cozimento.

Para força de cisalhamento não se observaram diferenças $(p>0,05)$ entre níveis de lisina dietética, sexo e interação entre estas duas variáveis. A literatura é controversa quando se discute valores para força de cisalhamento, Bressan (1999), ao estudar o efeito de temperatura de resfriamento sobre o desenvolvimento das reações químicas pos-mortem da carne de frangos de corte, encontrou valores muito semelhantes aos encontrados neste trabalho. Contreras (1995) relatou valores variando entre 5,5 e $5,8 \mathrm{kgf} / \mathrm{g}$, para força de cisalhamento (textura) da carne de peito de frangos de corte. Já Lyon et al. (1985) encontraram valores bastante superiores, utilizando como referência $7,5 \mathrm{kgf} / \mathrm{g}$.

$\mathrm{Na}$ Tabela 4 encontram-se os valores de medidas físicas de carne de peito de aves com 28, 35 e 42 dias de idade.
Aos 28 dias de idade, somente foi encontrada diferença $(p<0,05)$ entre níveis de lisina para altura de peito, sendo que o nível normal do aminoácido apresentou maiores valores. Aos 35 dias de idade foram encontradas diferenças $(p>0,05)$ entre níveis de lisina para largura e comprimento de peito, com o nível de lisina recomendado apresentando maiores valores. Aos 42 dias de idade, houve diferença $(p<0,05)$ entre níveis de lisina para altura, largura e comprimento de peito, sendo que os maiores valores foram encontrados com o nível recomendado de lisina. Houve interação $(p<0,05)$ entre o nível recomendado de lisina e sexo para altura de peito com maiores valores para as fêmeas.

Estudando o efeito da linhagem e de diferentes níveis de lisina da dieta sobre as medidas físicas da carne de peito, Pavan et al. (2001) não encontraram diferenças entre os níveis de lisina utilizados. Ao avaliar comprimento e largura da carne de peito de frangos de corte, aos 42 dias de idade, criados em diferentes densidades Mendes et al. (2001) encontraram valores médios que se situam entres os limites

Tabela 4 - Altura, largura e comprimento de peitos de frangos de corte submetidos a níveis recomendados (LR) e superiores (LS) de lisina dietética

Table 4 - Height, width, length of breast fillets of broiler chickens fed recomended (LR) and high (LS) dietary lysine levels

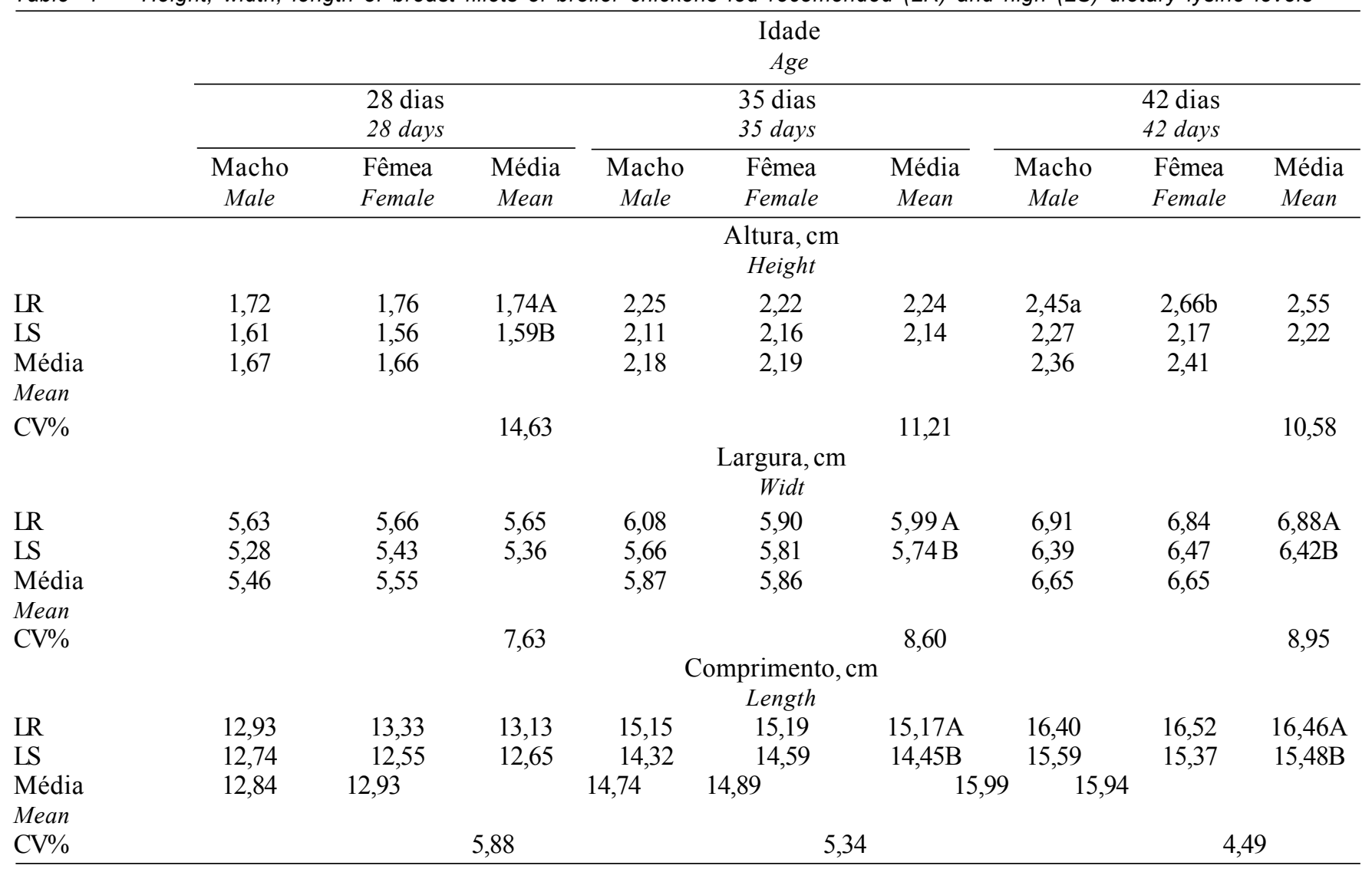

a,b $\mathrm{Na}$ linha, indica diferenças significativas entre sexos dentro de cada nível de lisina $(p<0,05)$; ${ }^{\text {, B }}$ na coluna, indica diferenças significativas entre níveis de lisina dentro de cada sexo $(p<0,05)\left({ }^{a, b}\right.$ in the line indicates significant differences between sexes form).

R. Bras. Zootec., v.31, n.4, p.1744-1752, 2002 
máximos e mínimos e obtidos para os tratamentos avaliados neste experimento.

$\mathrm{Na}$ Tabela 5 podem-se verificar os valores encontrados para a composição química da carne de peito de frangos de corte do presente experimento.

As idades influíram de forma quadrática $(\mathrm{p}<0,05)$ na porcentagem de umidade e matéria mineral, independentemente do nível de lisina utilizado. A umidade da carne de peito apresentou aumento dos 28 dias até os 35 dias de idade. A partir daí ocorre o decréscimo das porcentagens desse fator. Em relação à matéria mineral o comportamento apresentado é o mesmo que ocorreu com a umidade.

Para os fatores percentagem de proteína bruta e extrato etéreo, não houve influência $(p>0,05)$ de idade, lisina ou interação entre idades e níveis de lisina utilizados. Ao estudarem a composição química da carne de peito de frangos de corte sem pele e sem gordura, Sartori et al. (1997) obtiveram valores bastante semelhantes aos encontrados neste estudo.

O comportamento das variáveis e as respectivas equações de regressão estão apresentados nas Figuras 1 e 2.

Tabela 5 - Composição química do peito de frangos de corte submetidos a níveis recomendados (LR) e superiores (LS) de lisina dietética

Table 5 - Chemical composition of breast meat of broiler chickens fed recommended (LR) and high (LS) dietary lysine levels

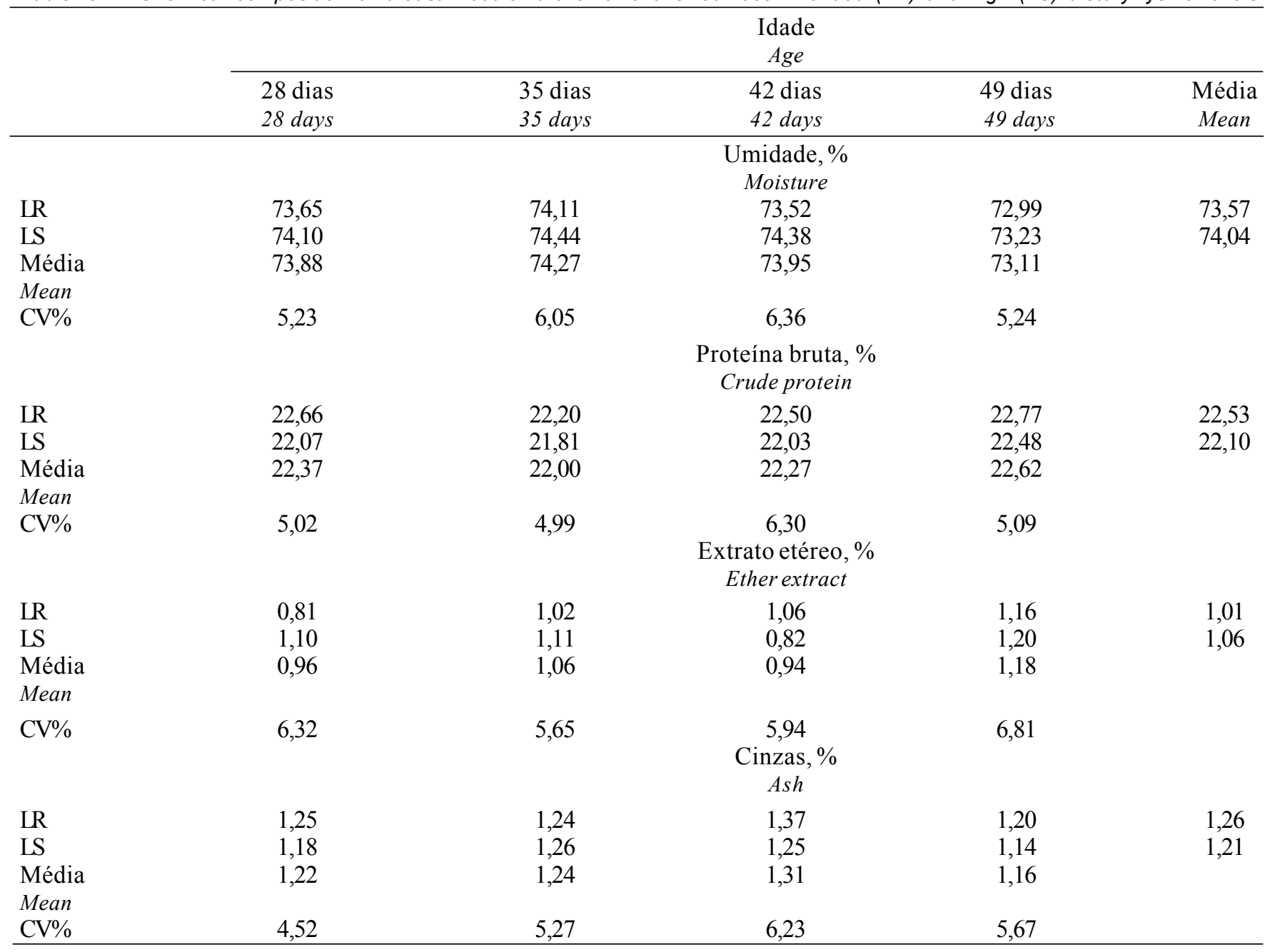




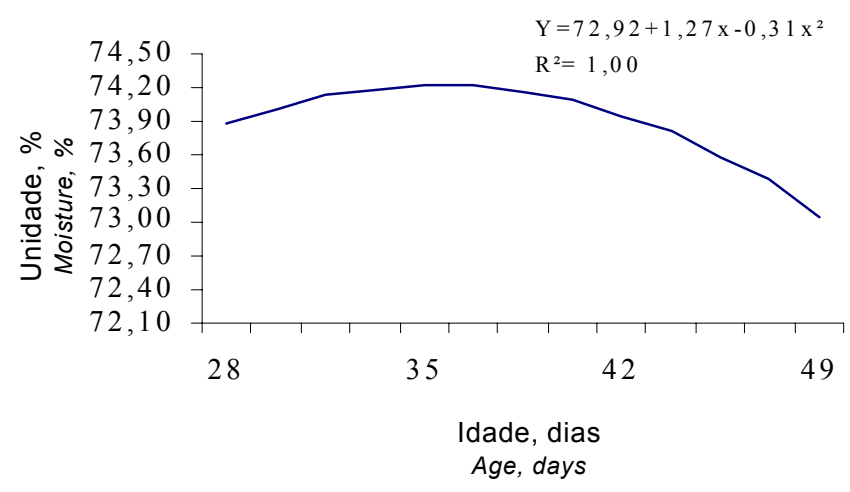

Figura 1 - Efeito da idade sobre a porcentagem de umidade da carne de peito de frangos de corte alimentados com níveis recomendados e superiores de lisina.

Figure 1 - Effect of age on moisture percentage of breast meat of broiler chickens fed recommended and high dietary lysine levels.

\section{Conclusões}

O nível superior de lisina testado não causou efeitos que justifiquem a adição de lisina sintética além do nível recomendado.

\section{Literatura Citada}

ASSOCIATION OF OFFICIAL AGRICULTURAL CHEMISTS - AOAC. Official methods of analysis. 11.ed. Washington, D.C.: 1990. 1141p.

BRESSAN, C. Efeito dos fatores pré-abate sobre a qualidade dos peitos de frango. Campinas: Universidade de Campinas, 1998. 179p. Tese (Doutorado em Tecnologia de Alimentos) - Universidade de Campinas, 1998.

CONTRERAS, C.J.C. Efeitos do atordoamento elétrico, estimulação elétrica e da desossa à quente na qualidade da carne do peito de frango "pectoralis major". Campinas: Universidade de Campinas, 1995. 150p. Tese (Mestrado em Tecnologia de Alimentos) - Universidade de Campinas, 1995.

EUCLIDES, R.F. SAEG - Sistema para Análises Estatísticas e Genéticas. Viçosa, MG: Universidade Federal de Viçosa, 1983. 62p

FRONING, G.W.; BABJI, A.S.; MATHER, F.B. The effect of preslaughter temperatures, stress, struggle and anesthetiztion on color and textural characteristics of turkey muscle. Poultry Science, v.57, n.3, p.630-633, 1978.

HONIKEL, K.O. The water binding of meat. Fleischwirttsch, v.67, n.2, p.1098-1102, 1987.

HICKLING, D.; GUENTER, W.; JACKSON, M.E. The effect of dietary methionine and lysine on broiler chicken performance and breast meat yield. Canadian Journal of Animal Science, v.70, p.673-678, 1990.

HOLSHEIMER, J.P.; RUESINK, E.W. Effect on performance, carcass composition, yield and financial return of dietary energy and lysine levels in starter and finisher diets fed to broilers. Poultry Science, v.72, n.5, p.806-815, 1993.

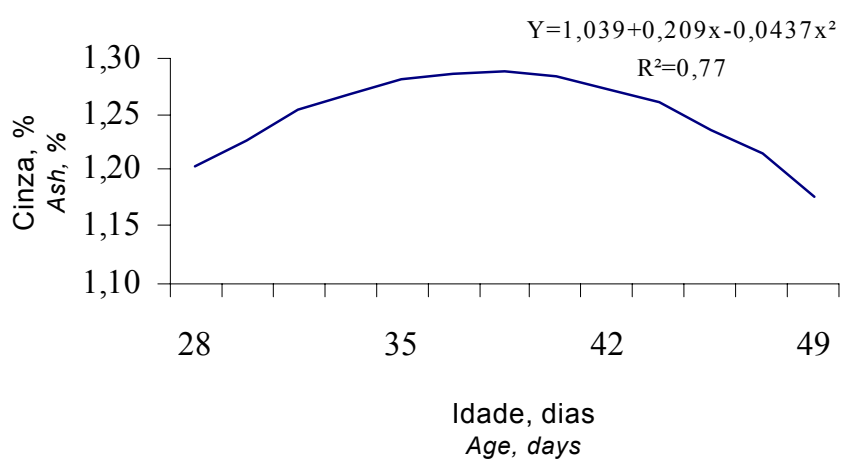

Figura 2 - Efeito da idade sobre a porcentagem de matéria mineral da de peito de frangos de corte alimentados com níveis recomendados e superiores de lisina.

Figure 2 - Effect of age on ash percentage of breast meat of boiler chickens fed diets with recommended and high lysine levels.

JONES, J.M.; GREY, T.C. Influence of processing on product quality and yield. Processing of Poultry, p.127-130, 1989

KIM, J.W.; FLETCHER, D.L.; CAMPION, D.R. Effect of electrical stunning and hot deboning on broiler breast meat characteristics. Poultry Science, v.67, n.7, p.674-676, 1988.

LEHNINGER, A.L.; NELSON, D.L.; COX, M.M. Princípios de bioquímica. 2.ed. São Paulo: Savier, 1995. 839p.

LYON, C.E.; HAMM, D.E.; THOMSON, J.E. pH and tenderness of broiler breast meat deboned various times after chilling. Poultry Science, v.64, n.2, p.307-310, 1985.

LUBRITZ, S.L. An statistical model for white meat yield in broiler. Journal of Applied Poultry Research, v.6, n.3, p.253-259, 1997.

MENDES, A.A. Efeito de fatores genéticos, nutricionais e de ambiente sobre o rendimento de carcaça de frangos de corte. Botucatu: Universidade Estadual Paulista, 1990. 103p. Tese (Livre Docência) - Universidade Estadual Paulista, 1990.

MENDES, A.A.; MOREIRA, J.; GARCIA, R.G. et.al. Avaliação do rendimento e qualidade da cane de peitoi em frangos de corte criados com diferentes densidades e níveis de energia na dieta. In: CONFERÊNCIA APINCO DE CIÊNCIA E TÉCNOLOGIA AVÍCOLAS, 2001, Campinas. Trabalhos de Pesquisa... Campinas: Fundação APINCO de Ciência e Tecnologia Avícolas, 2001.p.38.

MORAN, E.T. Nutrição e sua relação coma qualidade de carcaça de frangos de corte. In: CONFERÊNCIA APINCO DE CIÊNCIA E TECNOLOGIA AVÍCOLAS, 1992, Santos. Anais... Campinas: Fundação APINCO de Ciência e Tecnologia Avícolas, 1992. p.37-44.

NATIONAL RESERARCH COUNCIL - NRC. Nutrient requirements of poultry. 8 ed. Washington, D.C.: National Academy Press, 1984. 71p.

NATIONAL RESERARCH COUNCIL - NRC. Nutrient requirements of poultry. 9.ed. Washington, D.C.: National Academy Press, 1994. 155p.

PACK, M. Proteína ideal para frangos de corte. Conceitos e posição atual. In: CONFERÊNCIA APINCO DE CIÊNCIA E TECNOLOGIA AVÍCOLAS, 1995, Curitiba. Anais...

R. Bras. Zootec., v.31, n.4, p.1744-1752, 2002 
Campinas: Fundação APINCO de Ciência e Tecnologia Avícolas, 1995. p.95-110.

PAVAN, A.C.; MENDES, A.A.; ALMEIDA, I.C.L. et al. Efeito da linhagem e do nível de lisina da dieta sobe a qualidade da cane de peito de frangos de corte. In: REUNIÃO ANNUAL DA SOCIEDADE BRASILEIRA DE ZOOTECNIA, 38., 2001, Piracicaba. Anais... Piracicaba: Sociedade Brasileira de Zootecnia, 2001. p.886.

ROBINSON, F.E.; ROBINON, N.A.; TURNER, B.V. et. al. Breast muscle development in broilers as affected by strain, sex and age at processng. In: ANNUAL MEETING, 85., 1996, Louiseville. Proceedings... Louiseville: PSA, 1996. p.56.

SAMS, A.R.; MILLS, K.A. The effect of feed withdrawal duration on the responsiveness of broiler pectoralis to rigor mortis acceleration. Poultry Science, v.72, n.9, p.17891796, 1993.

SARTORI, J.R.; GONZALES, E.; SOUZA, E.M. et al. Efeito do período de jejum na fase de criação de frangos de corte machos sobre rendimento e composição de carcaça. Revista Brasileira de Zootecnia, v.26, n.6, p.1200-1207, 1997.
SUMMERS, J.D.; LEESON, S. Broiler carcass composition as affected by amino acid supplementation. Canadian Journal of Animal Science, v.65, n.3, p.717-723, 1985.

SUMMERS, J.D.; SPRATT, D.; ATKINSON, J.L. Broiler weight gain and carcass composition when fed diets varying in amino acid balance, dietary energy, and protein level. Poultry Science, v.71, n.2, p.263-273, 1992. 